\title{
Autosomal Dominant Polycystic Kidney Desease Coexisting with Renal Dysplasia. First Case Described and Followed Since Prenatal Period
}

\author{
Carmen Truyols \\ Hospital del Escorial
}

Corresponding author: Carmen Truyols

Departamento de Anestesiologia y

Reanimacion, Carretera de Guadarrama

al Escorial km 6,25, 28200 El Escorial

(MADRID) SPAIN

Tel: 0044669175157

E-mail:carmen.truyols@madrid.salud.org

Received: 15 October 2017

Revised: 19 March 2018

Accepted: 2 April 2018

This is an open-access article distributed under the terms of the Creative Commons Attribution Non-Commercial License (http:// creativecommons.org/licenses/by-nc/4.0/) which permits unrestricted non-commercial use, distribution, and reproduction in any medium, provided the original work is properly cited.
Autosomal dominant polycystic kidney disease (ADPKD) is the most frequent hereditary renal disease and causes terminal chronic renal failure. ADPKD is characterized by bilateral multiple renal cysts, which are produced by mutations of the PKD1 and PKD2 genes. PKD1 is located on chromosome 16 and encodes a protein that is involved in cell cycle regulation and intracellular calcium transport in epithelial cells and is responsible for $85 \%$ of ADPKD cases. Although nine cases of unilateral ADPKD with contralateral kidney agenesis have been reported, there have been no reports of early childhood ADPKD. Here, we report the only case of unilateral ADPKD with contralateral kidney dysplasia in the world in a four yearold girl who was intrauterinely diagnosed since she was 20 weeks old and followed for four years until present.

Key words: ADPKD, Agenesia, PKD1, Kidney, Polycystic

\section{Introduction}

Autosomal dominant polycystic kidney disease (ADPKD) is the most frequent hereditary renal disease which causes terminal chronic renal failure. It is characterized by bilateral multiple renal cysts produced by mutations to the genes PKD1 (85\%) and PKD2 (15\%).

Only 9 cases of unilateral ADPKD with agenesis of contralateral kidney have been reported all around the world, none of them were discovered before birth and none of them where described before having symptoms (Table $1)$.

We report the only case in the world of unilateral ADPKD with dysplasia of contralateral kidney in a 4-yr-old girl diagnosed intrauterine, since she was 20 weeks old and followed for 4 years until now.

\section{Case report}

A newborn female was studied in our hospital due to familiar history of ADPKD (father 38 years old had hypertension, grandmother and aunts had kidney transplantation in the last 10 years) and a renal dysplasia of the right 
kidney, diagnosed by prenatal ultrasound examination performed on the 20th week.

We proposed to have an amniocentesis to diagnosis ADPKD, but parents refused.

A new ultrasound examination done when newborn was 7 days old, revealed a $1 \mathrm{~mm}$ cyst in the left kidney.

It was decided to do a scintigraphy 1 month after born, to describe real renal function of the patient. The scintigraphy showed a severe affected right kidney represented by a little sheet of functioning tissue, and a tubular mass of the $10 \%$. Left kidney was morphologically normal and his function was above $90 \%$ (Fig. 1).

Newborn did not present any signs or symptoms of renal disease after birth, she was born with a normal birth weight and physical examination did not show any alteration. She did not present arterial hypertension. She presented a normal renal function, serum creatinine level 0' $5 \mathrm{mg} / \mathrm{dL}$, sodium $132 \mathrm{mEq} / \mathrm{L}$, and potassium $3 \mathrm{mEq} / \mathrm{L}$. Urinalysis

Table 1. Patients with ADPKD, and Contralateral Renal Agenesis Reported in the Literature

\begin{tabular}{|c|c|c|}
\hline Reference & $\begin{array}{l}\text { Diagnosis } \\
\text { age }\end{array}$ & Renal function \\
\hline Bear, 1974 (1) & 48 years & CRF at 58 years old \\
\hline Todorov,1999 (2) & 45 years & CRF at 45 years old \\
\hline Jeong, 2003 (3) & 66 years & CRF at 66 years old \\
\hline Sirvent, 2006 (4) & 23 years & CRF at 34 years old \\
\hline Poster, 2009 (5) & 23 years & Normal renal function when described \\
\hline Poster, 2009 & 38 years & Normal renal function when described \\
\hline Poster, 2009 & 40 years & Normal renal function when described \\
\hline Peces, 2012(6) & 41 years & CRF at 57 years old \\
\hline Krzemień, 2017 (7) & 12 years & Normal renal function when described \\
\hline Truyols, 2018 & 20 weeks & Normal renal function when described \\
\hline
\end{tabular}

Abbreviations: CRF, chronic renal failure. didn't show hematuria, or proteinuria. She did not present any urinary infection in her first years.

After she was born her family decided to make a genetic study of the whole family, which shows a PKD1 mutation in three generations, including our patient.

At the moment the 4 yr-old child does not present any symptom, last ultrasound examination shows an increased $2 \mathrm{~mm}$ cyst in the left kidney with no other alterations. Renal function, blood pressure and analytic parameters are absolutely normal.

\section{Discussion}

ADPKD, with an incidence as high as 1:400, affects more than 13 million individuals worldwide, and accounts for $7-10 \%$ of end stage kidney disease (ESKD) in adults ${ }^{1)}$.

Over the past 20 years, it has become clear that ADPKD, previously known as "adult polycystic kidney disease" is an important clinical entity in the pediatric population which affect all age groups children.

Indeed, $60 \%$ of children younger than 5 years of age, and 75 to $80 \%$ of children 5 to 18 years of age with a PKD- 1 mutation have renal cysts detectable by ultrasound studios ${ }^{2,3)}$.

Renal cysts in children with ADPKD have been associated with a wide clinical spectra, totally asymptomatic patients to those who present massive renal enlargement, hypertension, oliguria, and pulmonary hypoplasia.

We described the first case in the world of unilateral ADPKD diagnosed in the pregnancy. There are 8 cases of unilateral ADPKD described all around the world, but none of them have been described or followed since born.

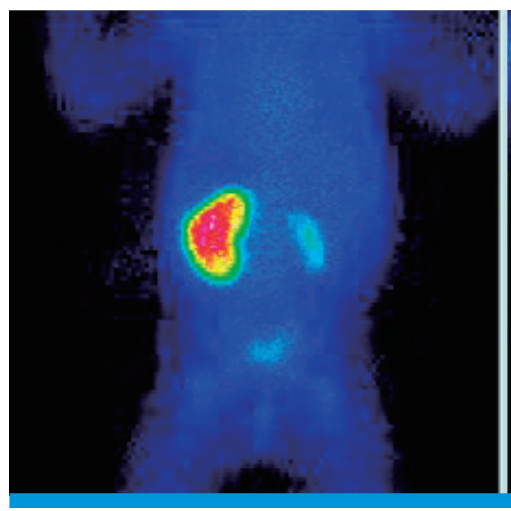

Fig. 1. Renal scintigraphy.
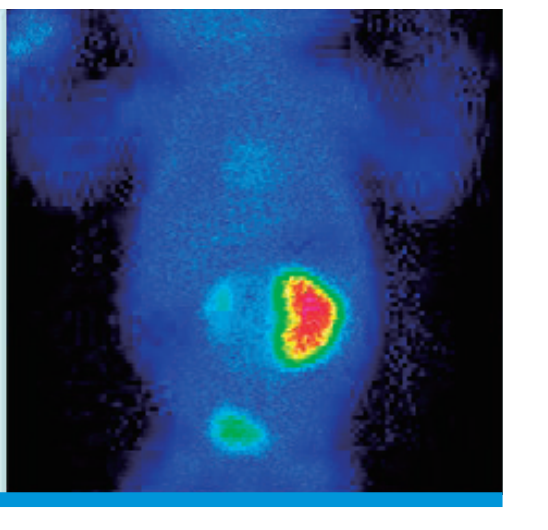
(Table 1).

Unilateral renal agenesis occurs in approximately 1 in 1000 births, and is generally a sporadic anomaly. Except for ectopia, malrotation or hydronephrosis, abnormalities of the contralateral kidney are infrequent. Unilateral renal agenesis is usually asymptomatic.

At the moment, it doesn't exist any verified information about unilateral ADPKD evolution, prognosis, or treatment, because cases are not being reported in a sufficient quantity, but, as much as prenatal diagnosis has being improved, unilateral ADPKD cases could be published and studied, and that would be a great tool in the future to investigate and advance in one of the most important genetic renal illness worldwide.

We remark the importance of report this case because there are not clear rates of morbidity or mortality of these patients. It is necessary, to have a real information about prognosis in unilateral ADPKD with contralateral agenesis.

\section{Conflicts of interest}

No potential conflict of interest relevant to this article was reported.

\section{References}

1. Bear RA. Solitary kidney affected with polycystic disease: a report of 2 cases. J Urol 1974;111:566-7.

2. Todorov VV. The diagnostic dilemma of the unilateral cystic kidney-ADPKD with aplasia of one kidney. Nephrol Dial Transplant 1999;14:2775.

3. Jeong GH, Park BS, Jeong TK, Ma SK, Yeum CH, Kim SW, et al. Unilateral autosomal dominant polycystic kidney disease with contralateral renal agenesis: a case report. J Korean Med Sci 2003;18:284-6.

4. Sirvent AE, Enríquez R, Ardoy F, Amorós F, González C, Reyes A. Autosomal dominant polycystic kidney disease with congenital absence of contralateral kidney. Int Urol Nephrol 2006;38:773-4.

5. Poster D, Kistler AD, Krauer F, Blumenfeld JD, Rennert H, Weishaupt et al. Kidney function and volume progression in unilateral autosomal dominant polycystic kidney disease with contralateral renal agenesis or hypoplasia: a case series. Am J Kidney Dis 2009;54:450-8.

6. Peces R, Vega C, Aguilar A, Zometa R, Tapia C, Peces C, et al. Autosomal dominant polycystic kidney disease with contralateral renal agenesis. Nefrologia 2012;32:839-42.

7. Krzemień G, Turczyn A, Pańczyk-Tomaszewska M, JakimówKostrzewa A, Szmigielska A.Long-term follow up of a boy with unilateral autosomal dominant polycystic kidney disease and contralateral renal agenesis. Journal of Applied Genetics 2006; 47:171-6. 